\title{
Freshwater Purification by Vacuum Airlift Column Using Methyl Isobutyl Carbinol and Casein
}

\author{
Allatchi Hassan Barkaï, Mahmoud El Hajem, Djimako Bongo, Jean-Yves Champagne \\ Laboratoire de Mécanique des Fluides et d’Acoustique, UMR 5509, CNRS/Université de Lyon/Ecole Centrale de Lyon/Université \\ Lyon 1/INSA Lyon, Villeurbanne, France \\ Email: *allatchi.hassan-barkai@insa-lyon.fr, mahmoud.elhajem@insa-lyon.fr,djimako.b5@gmail.com, \\ jean-yves.champagne@insa-lyon.fr
}

How to cite this paper: Barkaï, A.H., El Hajem, M., Bongo, D. and Champagne, J.-Y. (2019) Freshwater Purification by Vacuum Airlift Column Using Methyl Isobutyl Carbinol and Casein. Open Journal of Applied Sciences, 9, 230-239.

https://doi.org/10.4236/ojapps.2019.94019

Received: February 28, 2019

Accepted: April 20, 2019

Published: April 23, 2019

Copyright () 2019 by author(s) and Scientific Research Publishing Inc. This work is licensed under the Creative Commons Attribution International License (CC BY 4.0).

http://creativecommons.org/licenses/by/4.0/

\section{Open Access}

\begin{abstract}
Water purification by foaming in a bubble column is a major challenge for research. It leads to the development of innovative airlift column operated under depression. Sea water clarification by bubble column is well documented, but for freshwater remains insufficiently studied. Extraction of suspended clay particles in freshwater is carried out in an airlift column. The system used is under depression and operates in a closed circuit, thanks to a recirculation tank. Methyl isobutyl carbinol (MIBC) and soluble casein are used as surfactants to allow extraction. Clay used is fine and ultra-ventilated and a turbidimeter is used to measure turbidity. This study showed that the combined use of methyl isobutyl carbinol and casein in the airlift column makes it possible to completely clarify water loaded with clay particles. A turbidity of less than 1 NTU is obtained after 30 minutes of extraction.
\end{abstract}

\section{Keywords}

Vacuum Airlift Column, MIBC, Casein, Turbidity, Clay, Surfactant

\section{Introduction}

Suspended solid particles extraction in a liquid by the air flotation technique dispersed through airlift columns is a very promising water treatment technique. Several studies have highlighted the exceptional abilities of this technique [1]-[7]. Dispersed air flotation technique has been successfully applied in several processes including fish farming water treatment [8] [9] [10] [11]; extraction of bacteria and viruses [3] [5] [10] [12]; Microalgae and pest extraction [13] [14] 
[15]; removal of dissolved protein [16]. Lockwood et al., [17] note that solid-liquid separation by foaming requires finding substances of interest to have surface activity to form a stable foam.

Analysis of foams formed in polluted fish farming waters revealed that organic proteins present in these waters, play a leading role in the concentration of suspended solid particle [18] [19]. In contrast to surfactants with simple molecular structure, the protein consists of a polypeptide chain with 20 types of amino acids and surface activity.

The first studies of solid-liquid separations focused on the foaming extraction of dissolved proteins using airlift columns. The principle is to generate a foam through an air bubbling mechanism in a protein solution [1] [2]. Subsequently, with the aim of improving the process of intensive fish farming in aquaculture, bubble column recirculation systems have been studied and put in place to purify and/or enrich the water with oxygen [20] [21]. Suzuki et al., [20] used airlift column technology to remove colloidal substances generated by fish mucus in an aquaculture farm. This ability of bubble columns to separate solid particles from a liquid fluid has also been demonstrated by Park et al., [22]. These studies led to the development of an air-lift column equipped for foam separation and diversified their fields of application.

As solid particles in suspensions are hydrophilic, it's accepted that protein surfactants as well as polysaccharides which are at the origin of foam formation, transform the hydrophilic interface of these particles into a hydrophobic interface. As a result of this interface transformation, hydrophobic-interface particles become adsorbent to the air bubble interface and thus allow their separation by foaming [5].

For sea water clarification, the process does not require the use of surface-active substances, but for the clarification of freshwaters, it is essential to use surface-active products in order to ensure solid-liquid separation by airlift. Vacuum airlift column is an innovation of the Laboratory of Fluid Mechanics and Acoustics of the INSA-Lyon and of the French Research Institute for the Exploitation of the Sea (IFREMER). The vacuum airlift technique has the advantage of being simple and economical.

Barrut et al. [11] evaluated the effectiveness of solid-liquid separation by air lift under depression. Their work focused on the extraction of polluting particles in a recirculated aquaculture system. They have demonstrated experimentally that in fresh water, the operation of the air-lift under vacuum is impaired by the impossibility of generating fine bubbles and foam in the column. In the absence of saline water, only the addition of surfactants makes it possible to obtain a good extraction efficiency by airlift.

Thus, in the context of this study, two surfactant substances are combined to ensure the clarification of water loaded with fine ultra-ventilated clay particles suspended in ordinary water. The first one is soluble casein, a molecule extracted from milk, which was tested in the framework of the solid-liquid separation by 
bubble column by Suzuki and Maryuama [6] as well as Suzuki et al., [5]. The second surfactant used is methyl isobutyl carbinol, it's an alcohol mainly used in the additive synthesis for lubricant and flotation agent in mines.

The study we present in this paper aims to highlight the capabilities of a vacuum bubble column to be able to ensure the function of solid-liquid separation in fresh water using surfactants. To our knowledge, there are no other studies on the capabilities of a vacuum bubble column to provide the foaming-frothing function in freshwater. This study aims to fill this gap.

\section{Methods and Materials}

\subsection{Vacuum Airlift Column}

The experimental device is shown in Figure 1. This device consists of a vacuum airlift column, a vacuum pump, a bubble injection system and several measuring devices for the study of diphasic flows. This is airlift column model is transparent, made of plexiglass and connected to a recirculation basin called raceway, also transparent. The column height is set to $3 \mathrm{~m}$, at its top, it is equipped with anextraction system for the foam, equipped with a valve for collecting the entire extracted phase.

The different components for the airlift are:

- Two concentric vertical tubes equipped with pressure taps.

- A column base consisting of a square bottom containing the bubble diffusers and connected to the raceway via two PVC pipes.

- A column cone shaped head for retrieving the formed foam enriched with solid particles.

- A plexiglass crop tray connected to the cone by a flexible pipe.

The recirculation raceway is made of transparent PVC. The liquid effluent is first spilled into this raceway before it passes through the column. The tank has a 104 liters capacity and is connected to the base of the vacuum column by two 50 $\mathrm{mm}$ PVC pipe. The inlet pipe to the column is connected to the inner tube of the airlift column and the return pipe to the tank is connected to the outer tube of the airlift. A BUSH brand vacuum pump connected to the column through the harvest tray allows putting the column under depression, to ensure the harvest of suspended particles as part of the solid-liquid separation.

\subsection{Instrumentation}

The measurement instrumentation consists of an ultrasonic flow meter mounted on the pipes connecting the raceway to the base of the column; a mass flow meter and a monometer for pressurized air measurements upstream of the column.

The air injection system consists of fine circuit and fine ceramic bubble diffusers. For air injection experiments in the column, the diffusers are connected to the laboratory compressed air supply. This compressed air passes through an oiling filter to get rid of its oil. In the process of evaluating the solid-liquid separation of the depression column, the experimental device consists of an air column under vacuum, thus measuring instruments specific to the separation function: 


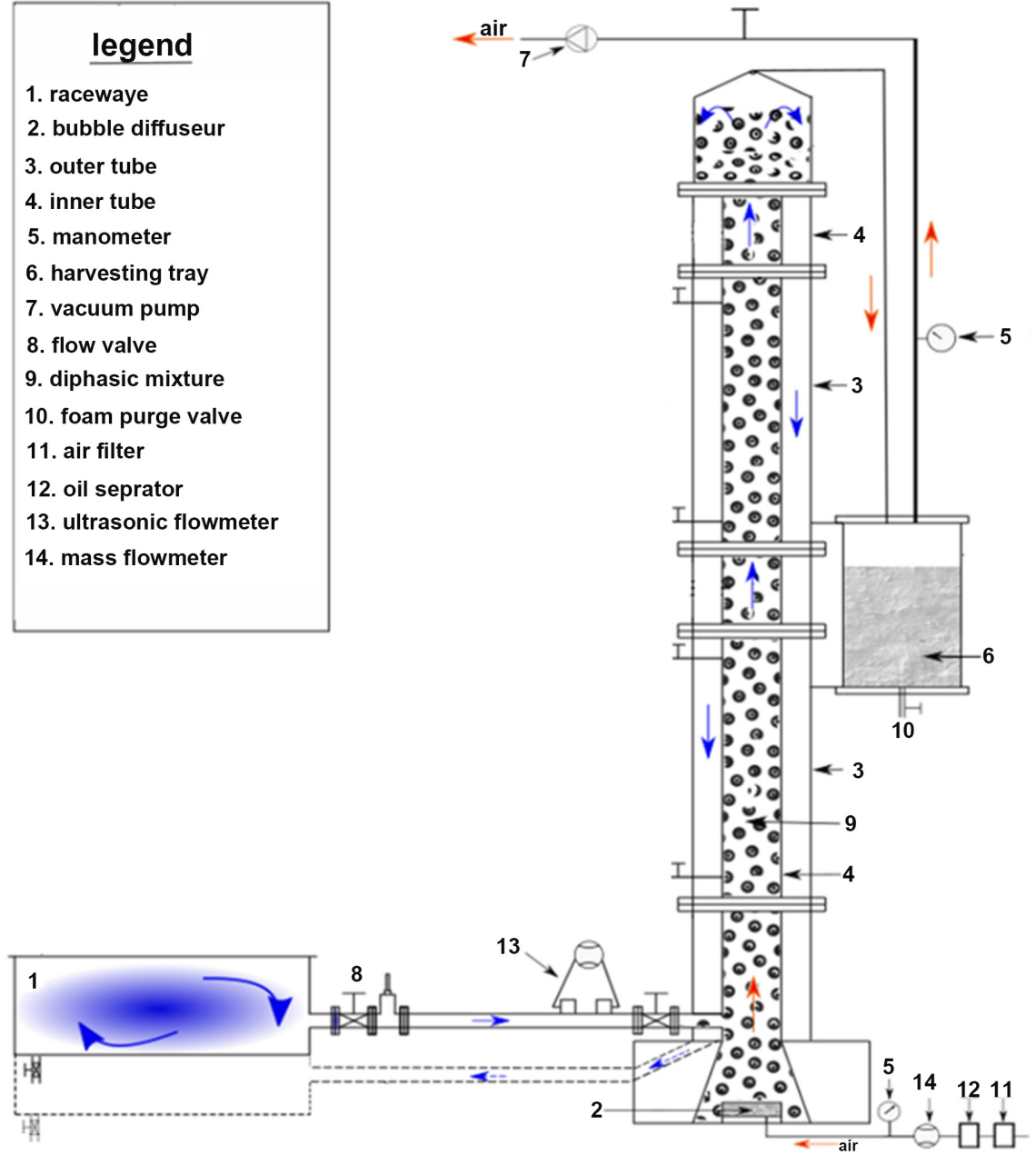

Figure 1. Experimental setup.

- One turbidity meter;

- A scale for measuring the mass of clay and casein;

- A blood pressure meter for measuring the surface tension of the liquid;

- A heated electrical stirrer for the preparation of the casein solution.

A turbidity meter is used to measure turbidity. The device used is PCE-TUM 20 characterized by an optical structure allowing it to read low values of turbidities $(0.00 \mathrm{NTU})$ as well as high values up to $1000 \mathrm{NTU}$. The unit of measurement adopted is the nephelometric turbidity unit (NTU). The calibration of the apparatus is carried out with two standard solutions supplied with the apparatus, including a standard solution of 0 NTU and a standard solution of 100 NTU.

\subsection{Surfactants}

In this experimental study, two surfactants are used to ensure the solid-liquid separation function of the airlift under depression. The first one is

4-Methyl-2-pentanol $\left(\mathrm{C}_{6} \mathrm{H}_{14} \mathrm{O}\right)$, methyl isobutyl carbinol (MIBC), it is an organic anionic surfactant and an alcohol used in the synthesis of corrosive additives for 
lubricants, paint or fine chemistry with a molar mass of $102.174 \mathrm{~g} \cdot \mathrm{mol}^{-1}$ and density is $0.8075 \mathrm{~g} \cdot \mathrm{cm}^{-3}$. At ambient temperature, it is a low viscosity, colorless and irritating liquid. Its toxicity level is $2.6 \mathrm{~g} \cdot \mathrm{kg}^{-1}$ for rats and $359 \mathrm{mg} \cdot \mathrm{l}^{-1}$ for fish. It should be noted that MIBC is very biodegradable, it decomposes to $94 \%$ in 20 days in the open air.

The second surfactant is casein, a natural protein extracted from milk. Proteins have characteristic functional properties regardless of their origin, plant (wheat, soy) or animal (milk). Casein derivatives are used as emulsifiers and foaming agents in many food systems. Its toxicity is very low, it is toxic beyond $1.10^{3} \mathrm{~g} \cdot \mathrm{kg}^{-1}$ for rats. An emulsifier normally acts as a surface active agent and allows the miscibility of two dissimilar liquids. Their emulsifying action is the result of a simultaneous presence in the molecule, of groups that attract oil (hydrophobic groups) and groups that attract water (hydrophilic groups). Their actions as emulsifying and stabilizing agents of emulsions are manifested by the reduction of surface tension due to the adsorption of emulsifiers to the water/oil interface and by extending their hydrophilic and hydrophobic fractions in the aqueous or oil/air phases, respectively. This action is all the more important since the molecule is linear and has a high adsorption value. A high concentration of emulsifying agent is required to form a viscous layer that allows for good stabilization of emulsions, stabilization of dispersions by decreasing the total free surface energy that limits coalescence and flocculation.

Once dissolved in the liquid phase, the proteins will gather at the gas-liquid interface, forming a mesh that will help stabilize the foam. In addition, the bubbles will begin to adopt a polyhedral shape, creating a flat strip at the intersection that will serve as a drainage channel. If the slats are broken the bubbles will coalesce and the suspended solids will gather at the interface of the new formed bubble.

\subsection{Experimental Protocol}

Extraction of clay particles in suspension is carried out with a mixture of fresh water and ultra-ventilated green clay with $20 \mu \mathrm{m}$ particles. The procedure of the solid-liquid separation process is made in four steps presented below.

In order to quantify the effect of these substances on liquid properties, surface tension measurements of the aqueous solution were carried out using the Kibron tensiometer. The results obtained are summarized in Table 1. It is found that the addition of MIBC or casein causes a decrease in the surface tension of the solution. In return the simultaneous presence of both surfactants reduces the surface tension but the reduction is less than the one caused by each product acting separately.

- Step 1: 104 liters of water are introduced into the experimental device added with $9.6 \mathrm{~g}$ of green clay. The mixture is initially stirred manually and thereafter, the column is started to ensure the homogenization of the clay with all the water contained in the base of the column and the raceway during five minutes with an air flow of $201 \cdot \mathrm{min}^{-1}$; 
Table 1. Surface tension measured by Kibron model tensiometer.

\begin{tabular}{cc}
\hline Solution & Surface tension \\
\hline Water & 72.20 \\
Casein & 50.40 \\
MIBC & 56.20 \\
Casein + MIBC & 63 \\
\hline
\end{tabular}

- Step 2: The next step is the preparation of the surfactant solutions and their addition to the effluent to be treated. For each additive, several concentrations have been tested in order to determine their impact on the separation function. For each one, the casein powder is dissolved and stirred in hot water and then poured into the raceway. The fluid contained in the column is homogenized by rising the water in the column put under depression using the vacuum pump. Once the column is brouzght back to the atmospheric pressure, the water of the column and the raceway mix. The repetition of this operation allows a better homogenization of the solution.

For MIBC, supplied in liquid form, the desired dose is introduced directly into the water. The mixing is done exactly as in the case of casein.

- Step 3: The next step is to take a first sample of the mixture to measure its initial turbidity which indicates the amount of solid matter in suspension. The turbidimeter is previously calibrated with buffer solutions.

- Step 4: This step consists in starting the process of solid-liquid separation by frothing-foaming. To do this, the vacuum pump is operated to raise the liquid level to the top of the airlift. Then the compressed air is injected into the column through the mass flow meter and the ceramic diffusers placed at the bottom of the column. Since the air flow is fixed, the valve of the vacuum pump is adjusted to maintain the level of the two-phase mixture at $20 \mathrm{~cm}$ above the inner tube.

\section{Results and Discussion}

MIBC is first tested as a surfactant in the process of extracting suspended clay particles. The experiment with several concentration of added MIBC was not satisfactory from the point of view of suspended particles separation. Foaming with MIBC is not very important and the harvest is very dilute and is not enriched with suspended particles. Even after two hours of column operation, a good separation efficiency could not be achieved. On the other hand, a reduction in the size and coalescence of bubbles is significantly observed.

Given these findings, it was decided to operate the column with a mixture of casein and MIBC. This combination MIBC + casein was made with an optimal dose of casein for extraction: $0.014 \mathrm{~g} \cdot \mathrm{l}^{-1}$. Experiments are conducted for two air flow rates: 15 and $20 \mathrm{l} \cdot \mathrm{min}^{-1}$. For each one, two doses of MIBC were tested: 0.005 and $0.003 \mathrm{ml} \cdot \mathrm{l}^{-1}$. The results of the tests are shown in Figure 2 and Figure 4. 
We note that for all the tests, the separation exceeds the $97 \%$ with however better results in the presence of $0.005 \mathrm{ml} \cdot \mathrm{l}^{-1}$ of MIBC for which turbidity is less than 1 NTU, the separation reaches $99 \%$ in 30 minutes (Figure 3 and Figure 4). This means that for the four combinations, the residual particles concentration is below the World Health Organization's water potability standard, which sets turbidity at $2 \mathrm{NTU}$ for drinking water.

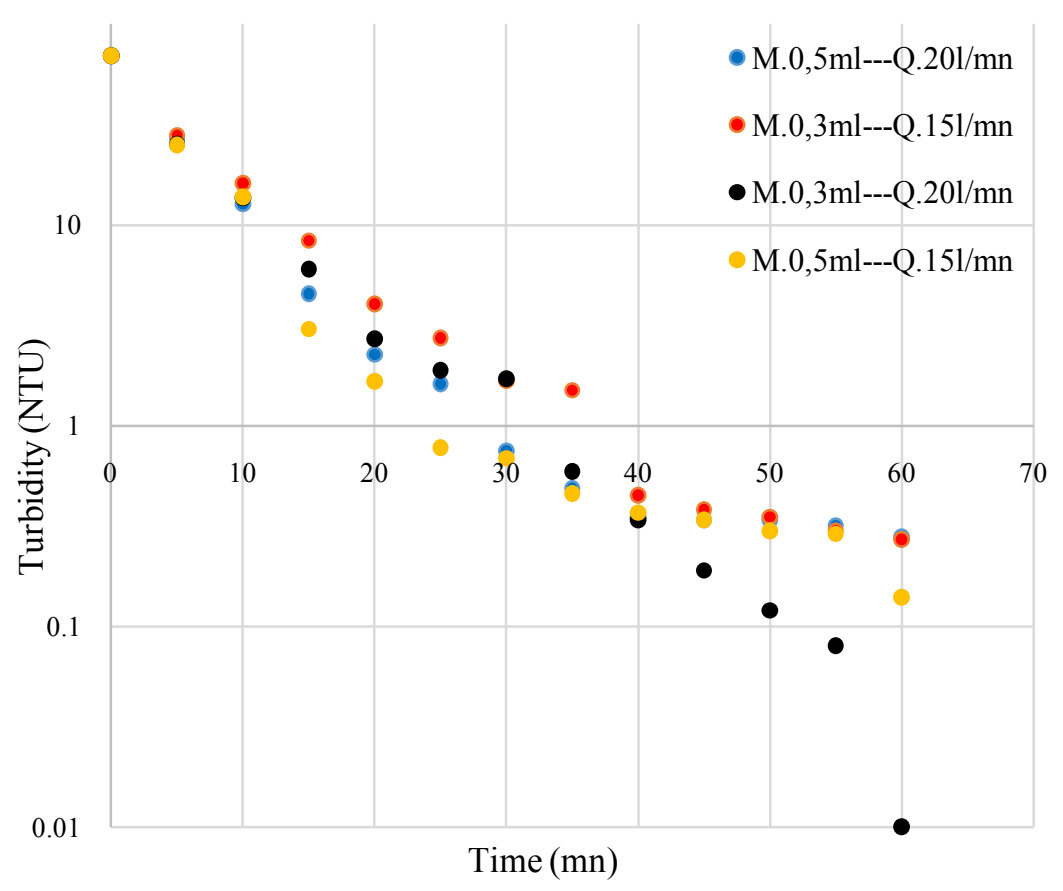

Figure 2. Clay particles extraction with MIBC + casein $\left(0.014 \mathrm{~g} \cdot \mathrm{l}^{-1}\right)$.

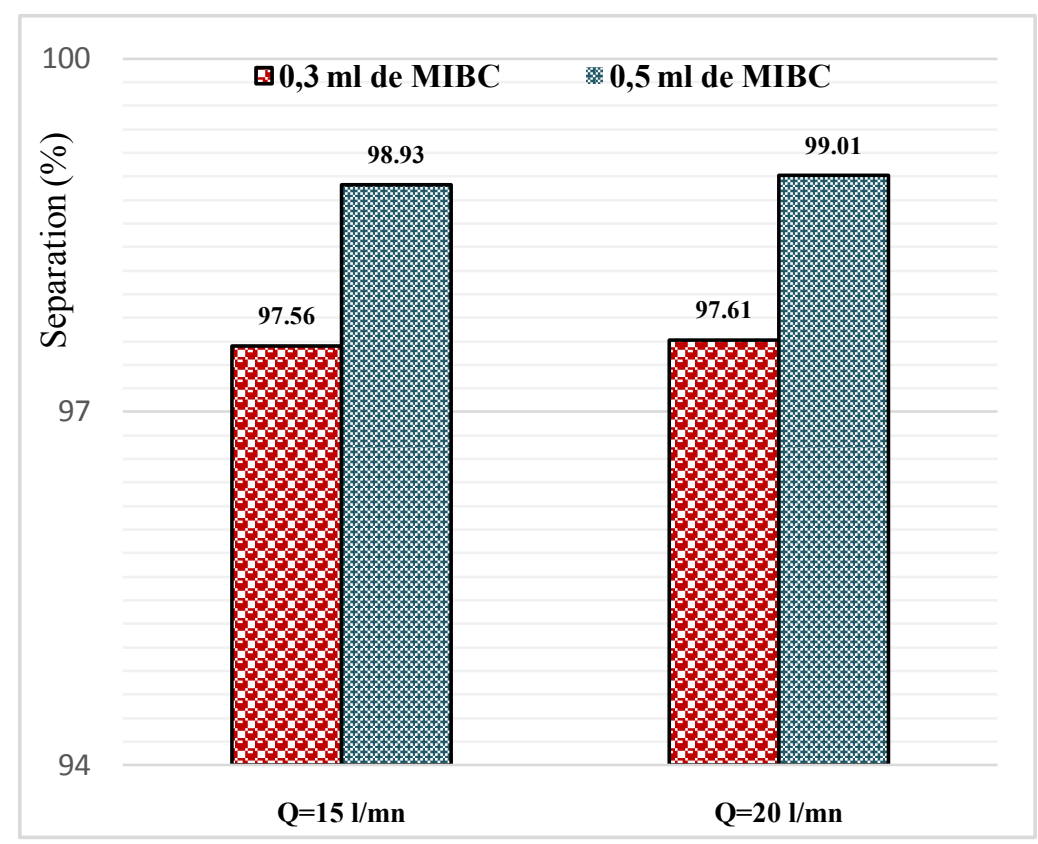

Figure 3. Efficiency of MIBC separation from clay particles (0.014 g. $\mathrm{l}^{-1}$ casein). 


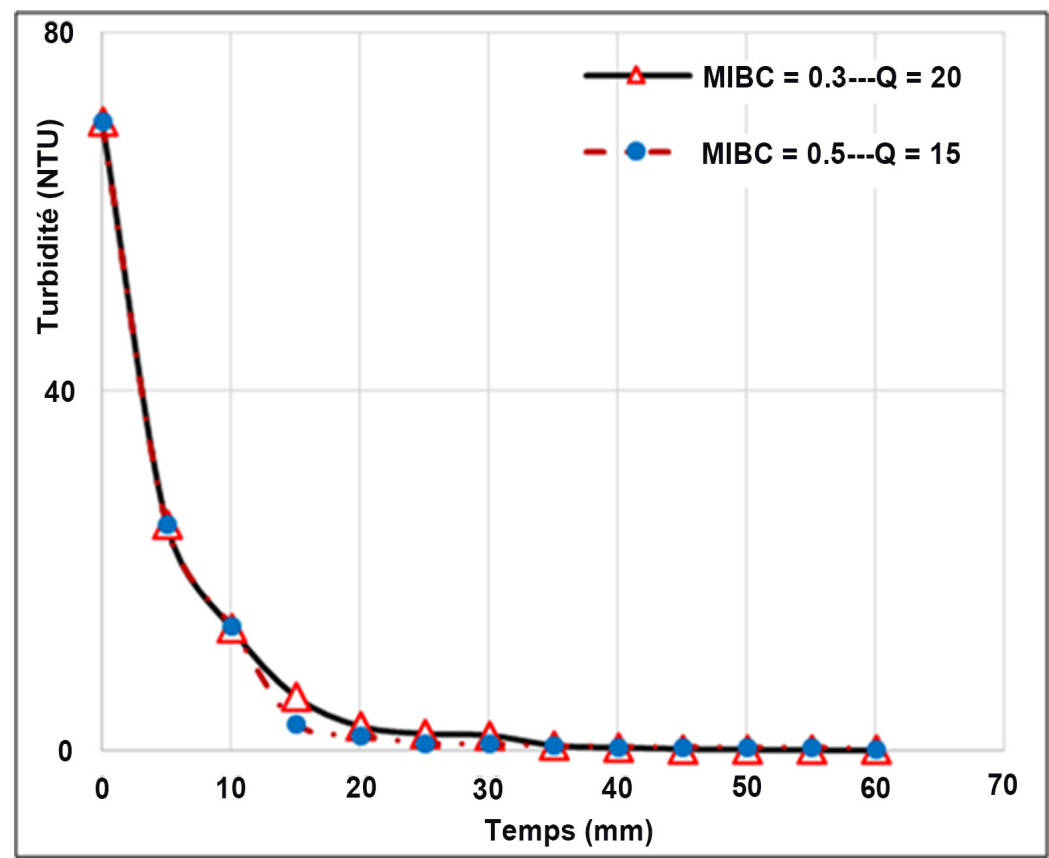

Figure 4. Efficacity of clay particles extraction by combined MIBC and casein.

During the first ten minutes of extraction (Figure 2), the combinations have almost the same efficiency. From the 10th minute onwards, a gap is observed and after thirty minutes of extraction, the two combinations with the MIBC at $0.5 \mathrm{ml}$ clarify the water with a final turbidity of less than 1 NTU. At thirty-five minutes, a third combination joins the previous two with the same extraction efficiency.

\section{Conclusions}

Soluble casein and MIBC used as surfactants in the dispersed air flotation foaming process gave excellent solid-liquid separation efficiency. This study has demonstrated the enormous potential of vacuum airlift column to ensure solid-liquid separation of suspended particles in fresh water. Reduction of turbidity is greater than $99 \%$. The results clearly show that the vacuum airlift column can completely clarify the water charged with suspended clay particles after $30 \mathrm{mi}-$ nutes in the case of the actual column prototype.

For future studies on the vacuum airlift column, it would be important to evaluate the liquid-liquid separation capabilities of this bubble column. Also, further study of the concentration of solid particles in the foam could provide a better understanding of the foaming process and further improve the extraction device.

Finally, as the surfactants are accessible at low cost, in large quantities and are especially weakly toxic, the vacuum airlift column system may well be deployed in rural areas where people have difficulty in accessing drinking water and are often forced to consume water contaminated with suspended particles.

\section{Conflicts of Interest}

The authors declare no conflicts of interest regarding the publication of this paper. 


\section{References}

[1] Schütz, F. (1937) Adsorption on Foam. Nature, 139, 629-630. https://doi.org/10.1038/139629a0

[2] Schnepf, R.W. and Garden, E.L. (1959) Foam Fractionation of Proteins: Concentrations of Bovine Serum Albumin. Journal of Biochemical and Microbiological Technology and Engineering, 1, 1-11. https://doi.org/10.1002/jbmte.390010102

[3] Timmons, M.B. (1994) Use of Foam Fractionation in Aquaculture. In: Timmons, M.B. and Losordo, T.M., Eds., Aquaculture Water Reuse System: Engineering Design and Management, Elsevier, Amsterdam, 247-279.

[4] Suzuki, Y. and Maruyama, T. (2002) Removal of Suspended Solids by Coagulation and Foam Separation Using Surface-Active Protein. Water Research, 36, 2195-2204. https://doi.org/10.1016/S0043-1354(01)00439-0

[5] Suzuki, Y., Hanagasaki, N., Furukawa, T. and Yoshida, T. (2008) Removal of Bacteria from Coastal Seawater by Foam Separation Using Dispersed Bubbles and Surface-Active Substances. Journal of BioScience and BioEngineering, 105, 383-388. https://doi.org/10.1263/jbb.105.383

[6] Maruyama, H., Seki, H., Suzuki, A. and Inoue, N. (2007) Batch Foam Separation of a Soluble Protein. Water Research, 41, 710-718.

https://doi.org/10.1016/j.watres.2006.07.017

[7] Park, J., Kim, Y., Kim, P.-K. and Daniels, H.V. (2011) Effects of Two Different Ozone Doses on Seawater Recirculating Systems for Black Sea Bream Acanthopagrus schlegeli (Bleeker): Removal of Solids and Bacteria by Foam Fractionation. Aquacultural Engineering, 44, 19-24.

https://doi.org/10.1016/j.aquaeng.2010.11.001

[8] French, K., Guest, R.K., Finch, G.R. and Haas, C.N. (2000) Correlating Cryptosporidium Removal Using Dissolved Air Flotation in Water Treatment. Water Research, 34, 4116-4119. https://doi.org/10.1016/S0043-1354(00)00164-0

[9] Muniain-Mujikaa, I., Gironesa, R., Tofino-Quesadaa, G., Calvob, M. and Lucenaa, F. (2002) Depuration Dynamics of Viruses in Shellfish. International Journal of Food Microbiology, 77, 125-133. https://doi.org/10.1016/S0168-1605(02)00052-1

[10] Suantika, G., Dhert, P., Sweetman, E., O’Brien, E. and Sorgeloos, P. (2003) Technical and Economical Feasibility of a Rotifer Recirculation System. Aquaculture, 227, 173-189. https://doi.org/10.1016/S0044-8486(03)00502-7

[11] Bertrand, B., Blancheton, J.-P., Muller-Feuga, A., René, F., Narváez, C., Champagne, J.-Y. and Grasmick, A. (2013) Separation Efficiency of a Vacuum Gas Lift for Microalgae Harvesting. Bioresource Technology, 128, 235-240. https://doi.org/10.1016/j.biortech.2012.10.056

[12] Brambilla, F., Antonini, M., Ceccuzzi, P., Terova, G. and Saroglia, M. (2008) Foam Fractionation Efficiency in Particulate Matter and Heterotrophic Bacteria Removal from a Recirculating Seabass (Dicentrarchus labrax) System. Aquacultural Engineering, 39, 37-42. https://doi.org/10.1016/j.aquaeng.2008.05.004

[13] French, K., Guest, R.K., Finch, G.R. and Haas, C.N. (2000) Correlating Cryptosporidium Removal Using Dissolved Air Flotation in Water Treatment. Water Research, 34, 4116-4119. https://doi.org/10.1016/S0043-1354(00)00164-0

[14] Teixeira, M.R. and Rosa, M.J. (2006) Integration of Dissolved Gas Flotation and Nanofiltration for M. aeruginosa and Associated Microcystins Removal. Water Research, 40, 3612-3620. https://doi.org/10.1016/j.watres.2006.06.006

[15] Teixeira, M.R., Sousa, V. and Rosa, M.J. (2010) Investigating Dissolved Air Flota- 
tion Performance with Cyanobacterial Cells and Filaments. Water Research, 44, 3337-3344. https://doi.org/10.1016/j.watres.2010.03.012

[16] Kumart, B.R. and Gandhi, K.S. (1997) Prediction of Separation Factor in Foam Separation of Proteins. Chemical Engineering Science, 52, 4625-4636. https://doi.org/10.1016/S0009-2509(97)00304-7

[17] Lockwood, C.E., Bummer, P.M. and Jay, M. (1997) Purification of Proteins Using Foam Fractionation. Pharmaceutical Research, 14, 1511-1515. https://doi.org/10.1023/A:1012109830424

[18] Maruyama, T., Okuzumi, M., Saheki, A. and Shimamura, S. (1991) The Purification Effect of the Foam Separating System in Living Fish Transportation and Preservation. Nippon Suisan Gakkaishi, 57, 219-225. https://doi.org/10.2331/suisan.57.219

[19] Chen, S., Timmons, M.B., Bisogni, J.J. and Aneshansley, D.J. (1993) Suspended-Solids Removal by Foam Fractionation. Progressive Fish-Culturist, 55, 69-75. https://doi.org/10.1577/1548-8640(1993)055<0069:SSRBFF>2.3.CO;2

[20] Suzuki, Y., Maruyama, T., Numata, H., Sato, H. and Asakawa, M. (2003) Performance of a Closed Recirculating System with Foam Separation, Nitrification and Denitrification Units for the Intensive Culture of Eel: Towards Zero Emission. $A q$ uacultural Engineering, 29, 165-182.

https://doi.org/10.1016/j.aquaeng.2003.08.001

[21] Blancheton, J.P., Piedrahita, R., Eding, E.H., Roque d'orbcastel, E., Lemarié, G., Bergheim, A. and Fivelstad, S. (2007) Intensification of Land Based Aquaculture Production in Single Pass and Reuse Systems. In: Bergheim, A., Ed., Aquaculture Engineering and Environment, Chapter 2, Research Signpost, Kerala, 21-47.

[22] Park, J., Kim, Y., Kim, P.-K. and Daniels, H.V. (2010) Effects of Two Different Ozone Doses on Seawater Recirculating Systems for Black Sea Bream Acanthopagrus schlegeli (Bleeker): Removal of Solids and Bacteria by Foam Fractionation. Aquacultural Engineering, 44, 19-24.

https://doi.org/10.1016/j.aquaeng.2010.11.001 